\title{
A POLÍCIA MILITAR FRENTE AO RACISMO E DISCRIMINAÇÃO
}

\author{
THE MILITARY POLICE IN FRONT OF RACISM AND DISCRIMINATION
}

\author{
Luiz Ricardo dos Santos ${ }^{1}$
}

RESUMO: As diferenças sociais entre brancos e negros são nítidas no cotidiano. Além do aspecto econômico, no qual pessoas pretas e pardas (a combinação desses grupos forma a classificação negra, segundo o IBGE) são maioria entre as que possuem rendimentos mais baixos, a persistência de situações de maior vulnerabilidade, indicada por evidências nos campos da educação, saúde, moradia, entre outros, mostram evidente desequilíbrio na garantia de direitos em prejuízo para a população negra. É possível também observar a sub-representação entre líderes de equipes nas empresas, juízes e políticos. Esse artigo aborda que o racismo é caracterizado pela opressão de uma etnia com mais "poder" sobre a outra. Quando se fala de racismo reverso, parte-se da ideia de que o grupo desfavorecido está oprimindo seu opressor. Um grupo étnico que sofreu mais de 300 anos de escravidão, fazendo parte de um dos últimos países do globo a abolir a escravatura - fato que tem apenas 130 anos -, certamente não teria a mesma força que seu opressor. Além de que existe o conceito de escravidão moderna - relações de trabalho em que pessoas são forçadas a exercer uma atividade contra a sua vontade mediante forma de intimidação.

Palavras-chave: Polícia Militar, Princípios Constitucionais. Racismo. Discriminação.

ABSTRACT: The social differences between whites and blacks are clear in everyday life. In addition to the economic aspect, in which black and brown people (the combination of these groups form the black classification, according to IBGE) are the majority among those with lower incomes, the persistence of situations of greater vulnerability, indicated by evidence in the fields of education, health, housing, among others, show evident imbalance in guaranteeing rights to the detriment of the black population. It is also possible to observe under-representation among team leaders in companies, judges and politicians. This article discusses that racism is characterized by the oppression of one ethnic group with more "power" over the other. When we talk about reverse racism, we start from the idea that the disadvantaged group is oppressing its oppressor. An ethnic group that suffered more than 300 years of slavery, being part of one of the last countries in the world to abolish slavery - a fact that is only 130 years old -, certainly would not have the same strength as its oppressor. In addition, there is the concept of modern slavery - work relationships in which people are forced to engage in activities against their will through forms of intimidation.

Keywords: Military Police, Constitutional Principles, Racism, Discrimination.

\footnotetext{
${ }^{1}$ Policial Militar da PMPR, Graduado do Curso de Administração de Empresas e administração Rural, Pós-graduado em Direito Ambiental e direito Militar, Armazenagem de grãos e Segurança alimentar, cursando Agronomia pela Universidade do Norte do Paraná - Bandeirantes-Pr.
} 


\section{INTRODUÇÃO}

Considero relevante lembrar que, como afirma Weber (2014), os fenômenos sociais são construídos enquanto objetos da análise e investigação científica a partir da perspectiva do investigador, ou seja, são parciais se relacionando a um interesse do pesquisador em investigar determinado fenômeno, considerado por ele significativo. Tal constatação implica na necessidade de construções teóricas e abordagens metodológicas cuidadosas e acuradas, de forma a possibilitar que o conhecimento científico não se confunda com os "juízos de valor" do pesquisador.

Para abarcar o estudo em questão usar-se-á como questão norte a seguinte indagação: de que forma o racismo ocorre no Brasil e como ele se justifica?

A relevância do trabalho também se espelha na questão de que não se pode exigir que a maioria da população aceite um discurso oficial que mantenha privilégios em detrimento de direitos, pois é acintosa a maneira como o atual governo vem tratando ou simplesmente desprezando temas fundamentais que os movimentos sociais levaram décadas para colocar em pauta, e é muito triste assistir à criminalização desses movimentos.

Não se pode condenar um povo inteiro a esperar por mais de século que a "evolução natural" da sociedade venha trazer-lhe dignidade e justiça, mais do que nenhum direito a menos, é preciso assegurar o pleno exercício da cidadania, com liberdade de expressão, de consciência e de crença, com a garantia de ir e vir, sem nenhum tipo de discriminação e com plena igualdade. Em referência à metodologia adotada, iniciou-se pela leitura, interpretações e extrações de textos de diversas obras bibliográficas e dispositivos legais, referente ao tema proposto.

\section{POLÍCIA MILITAR}

A Polícia Militar é um órgão estatal, cujo amparo legal se encontra previsto na Constituição Federal de 1988. É uma instituição organizada com base na hierarquia e na disciplina. As Polícias Militares do Estados são órgãos destinados a Segurança Pública, cujo respaldo legal encontra-se no artigo I44, inciso V, da referida Constituição. Portanto, sua função precípua advém da Carta Magna de 1988, especificamente no art. I44, § 5º tal parágrafo disciplina que a polícia ostensiva e a preservação da ordem pública é competência da Polícia Militar.

Sabe-se que a Segurança Pública é de fundamental importância para a construção e preservação de um Estado Democrático de Direito. E a Polícia Militar, inserida no contexto legal da segurança da população e das instituições, tem papel relevante a cumprir frente a sociedade. Por aí se pode julgar do valor da Polícia Militar, no que tange a Segurança Pública, tendo seus princípios básicos introduzidos pela Constituição Federal de 1988, que descreve o seu campo de 
atuação, bem como assegura a legitimidade de suas funções.

Como autarquia pertencente às entidades federativas do Estado Brasileiro as Polícias Militares subordinam-se aos Governadores dos Estados, do Distrito Federal e dos Territórios, conforme prevê a Carta Cidadã de 1988. A Polícia Militar tem suas funções de acordo com a ordem constitucional vigente emıg8, pois é esta que limita a sua atuação através dos princípios constitucionais, no qual ela é cumpridora e protetora. É uma organização que deve estar a serviço da cidadania, buscando sempre estabelecer um Estado Democrático por excelência, onde a democracia e o direito devem sempre se fazer presentes, pois Segurança Pública é atividade primordial para a sociedade.

Sem segurança não há dignidade da pessoa humana, muito menos Democracia. O presente trabalho consiste em método dedutivo e em pesquisa bibliográfica qualitativa, tendo seu desenvolvimento a partir da coleta de leis e decretos relativos às normas, diretrizes e definições inerentes a Polícia Militar. Para tanto, usou-se também estudos oriundos de artigos científicos publicados na internet, bem como em obras que tratam da Polícia Militar, cujos conteúdos têm relevância para atividade fim das Polícias Militares.

Conforme Bicalho (2015), as normas não garantem a prática, pois nas ações policiais ainda se observam à valorização do grupo de pertencimento, das táticas militares e de "combate". Portanto, a aplicação das funções de polícia tem mantido as características tradicionais. Ainda, conforme o autor acima citado é indispensável compreender o aparecimento de práticas policiais arbitrárias que insurgem contra quem é considerado ameaçador ou perigoso (pobres, negros, homoafetivos, entre outros).

Caberia à polícia coibir com base em construção de suposta dicotomia entre ordem e desordem, bom e mau, a partir da lógica argumentativa de que os indesejáveis colocam em risco a segurança de todos os cidadãos. É importante ressaltar que há policiais que desempenham a função com seriedade. Assim, Foucault (2015) afirma que as relações de poder permitem que surjam umas e não outras maneiras de ser policial.

Nesse contexto em que se encontra a sociedade o racismo e a discriminação constituemse dois expoentes dignos de análise, pois interferem de forma direta nas relações sociais e antropológicas.

\section{DISCRIMINAÇÃO E PRECONCEITO}

A discriminação racial no Brasil se faz presente em todos os âmbitos e esferas sociais. Essa presença de tão constante, em muitos momentos, passa despercebida, incorpora-se ao imaginário coletivo nacional, diluída pelos ideais hegemônicos da democracia racial, que colocam 
negros e brancos em posição de igualdade, flui livremente, transformando-se em pensamento social vigente. As estatísticas mais recentes, baseadas no IDH (Índice de Desenvolvimento Humano) têm confirmado o abismo social potencializado pelas identidades, em especial, raça e gênero, enfraquecendo no meio acadêmico, a ideia de paraíso racial (CARVALHO, 2016).

Os ideais da democracia racial que mascaram a sobreposição da branquitude, ainda permeiam as relações sociais. Mesmo que de forma banalizada e por força da evidente violência, o racismo tem sido discutido. A maneira como se reage, não. Subordinar-se a justificativa de que foi um suposto mal-entendido, esconder a dor e o sofrimento causados pela humilhação cotidiana de não ter seus direitos respeitados, ser conivente com a agressão, não traz proteção nem poupa aborrecimentos. Ao contrário, esse posicionamento torna perene a situação de subalternização da população negra e legitima o Estado de discriminação, reforçando posturas de alienação e vitimização.

Abordar o racismo à luz da legislação brasileira, ou seja, encará-lo como crime é uma das alternativas para exterminá-lo, legado este, da retomada de ação do movimento negro que a partir da década de 1970, marcou esse período com denúncias e ações na justiça contra as práticas discriminatórias raciais. Para tanto, é preciso apropriar-se dos direitos constituintes, enfrentar o medo da exposição pública e a recusa das instituições policiais em levar ao conhecimento das autoridades competentes atos de racismo, discriminação racial ou mesmo injúria racial. Posto que a discriminação racial é a prática do racismo e a confirmação do preconceito efetivamente (SANTOS; SILVA, 2015).

\section{I RACISMO}

Importante começarmos essa breve reflexão recordando que uma das mais profundas raízes de nossas desigualdades raciais encontra-se no período em que se o Brasil começava a sair do capitalismo escravagista para o capitalismo industrializado. Consorte (20II), em texto seminal sobre "A questão do negro", reflete como o pensamento hegemônico racista brasileiro no início do século XX defendia ter sido o fim da escravidão o máximo do resgate da dívida brasileira para com os negros que, a partir daquele momento, no campo e na cidade, os negros estariam totalmente inseridos à dinâmica capitalista, podendo "se integrar à sociedade como homens livres, com iguais direitos aos demais, sendo que seu futuro neste país, a partir de então, dependeria apenas de seu esforço" (CONSORTE, 20II, p. 86).

Enquanto estratégia social, econômica e política, o racismo tem assumido variadas formas de expressão, das mais sutis às mais explícitas, das individualizadas às institucionalizadas, em todas elas, alcançando uma eficiência letal no comprometimento das 
subjetividades atingidas, principalmente, pela violência simbólica de seus mecanismos de submissão e controle.

Em nosso cotidiano, há uma lista enorme de ações e intencionalidades que se configuram e se amalgamam no universo das práticas consideradas discriminatórias ou preconceituosas e que, estas quando ligadas a critérios de fenotipia como a cor da pele, a tessitura do cabelo, os traços corporais que denotam pertencimento a um determinado grupo étnico racial - negros, quilombolas, indígenas, ciganos - ou religioso - principalmente, no Brasil, das religiões de matrizes indígenas e africanas -, são consideradas racistas. Podemos exemplificar um extremo dessas práticas nas ações de grupos juvenis que pregam a intolerância e o extermínio de negros, homossexuais, nordestinos, mulheres e moradores de rua e que enchem as páginas policiais nos últimos anos.

O racismo institui leis, regras e mecanismos para manter o poder político e econômico concentrado nas mãos de um grupo que afirma superior, em detrimento da raça oprimida. Mas, antes, e aí está a sua força, o racismo cria mitos, padrões, critérios, estereótipos que definem valores morais e estéticos, conformando o que deve ser considerado como bom, bonito e correto e, consequentemente, o que não o é.

Mesmo que com todas as evidências, estudos e a criminalização de sua prática, o racismo ainda é localizado com "dificuldade" em nosso cotidiano, em nossas relações sociais e em nossas instituições. No cotidiano, tende-se a naturalizar as manifestações como sendo algo consensual, aceito e vivido por ambas as partes, "sem traumas"; nas relações interpessoais, o racismo não é percebido como determinante de escolhas afetivas - e muito menos das recusas - e acaba-se por, mais uma vez, naturalizar o que é indiscutivelmente uma construção social.

As diversas correntes teóricas perceberam o tema, que sempre girou em torno desses dois extremos, a mistura racial e a exclusão. Telles identifica três correntes de pensamento relativas ao tema racial: a primeira, que postula não haver discriminação racial e sim grande intercurso entre as raças; a segunda, que defende que a discriminação existe, mas que é um problema transitório; e a terceira, que entende que a discriminação racial é um problema estrutural e que persiste ao longo do tempo.

A primeira corrente, está associada a Gilberto Freyre e a brasilianistas como M. Harris, C. Degler e C. Wagley. Esses analistas acreditavam que a desigualdade racial era fruto da escravidão e que tendia a ser superada pelas relações fluidas entre as raças, pela ampla miscigenação. Percebe-se que essas análises enfatizavam as relações horizontais entre as raças e, nesse sentido, a desigualdade de classe é que representava um fator de hierarquização social e não as diferenças raciais.

A segunda corrente é representada por Florestan Fernandes que, como dissemos, via a Revista Ibero-Americana de Humanidades, Ciências e Educação. São Paulo, v. 6.n.12, dez. 2020. 
discriminação racial como um resquício da sociedade escravista, que tendia a desaparecer com o avanço do capitalismo. Diferentemente da corrente anterior, Fernandes não tomava a mistura racial como um valor, estando mais interessado, segundo Telles (2013) em questões relativas ao desenvolvimento e à igualdade racial.

A terceira corrente é representada, na visão de Telles (2013) por Carlos Hasenbalg, que defende que o racismo é compatível com o capitalismo, apontando ainda que a raça opera como um critério de hierarquização social que complementa a desigualdade de classe ou de posições sociais. Nos deteremos sobre as análises de Hasenbalg (2017) por acreditarmos que este autor apresenta considerações importantes sobre as relações raciais no Brasil, refletindo tanto sobre as análises da primeira quanto da segunda geração apresentadas acima.

Hasenbalg (2017) distingue duas correntes de pensamento que se detiveram sobre a análise das relações raciais no Brasil no pós-escravismo, a saber: a primeira, que considerava que as relações raciais constituíam um sistema de categorização social desenvolvido no período escravocrata e a segunda, que via as relações raciais como sobrevivências de padrões de relacionamento inter-racial desenvolvidos à época da escravidão. Entre os primeiros, o autor identifica M. Harris, C. Degler e H. Hoetink; no segundo grupo, está Florestan Fernandes.

$\mathrm{O}$ autor apresenta as ideias de $\mathrm{H}$. Hoetink sobre as relações raciais nas sociedades com passado escravocrata. Para este autor, o Brasil poderia ser caracterizado por uma sociedade segmentada racialmente, mas em que havia mobilidade social máxima e por gradações, ou seja, a possibilidade de ascensão social para os negros era grande e se baseava no contínuo de cor da população, aspecto possibilitado sobretudo pela existência de um segmento de cor intermediário, que Hoetink chama de mulatos.

Assim, o autor defende que há um desenvolvimento de uma estrutura sócio racial distinta da estrutura de estratificação econômica, a primeira composta pelas representações subjetivas dos brancos sobre os diferentes grupos sociais e a segunda caracterizada pela prosperidade econômica e ascensão social. É preciso lembrar que esta caracterização tem como ponto de partida a consideração de relações raciais horizontais, mais fluidas e menos conflituosas.

Para Hasenbalg, esta análise negligencia questões da estrutura de classes, além de separar de maneira inadequada as relações raciais no período do escravismo e as relações sociais após o fim da escravidão, por considerar que a relação de dominação estabelecida entre negros e brancos tivesse terminado com a abolição, quando, na verdade, esta relação permeava toda a organização social. Segundo Hasenbalg,

O escravismo não apenas condicionou a estrutura de classes e o sistema de disciplina de classe e de raça aos quais toda a população livre estava sujeita, mas também influenciou o destino social dos escravos alforriados e dos nãobrancos nascidos livres, sob vários aspectos” (HASENBALG, 2017, p. 69) 
Além disso, o autor defende que considerar o sistema de classificação racial como autônomo com relação ao sistema de estratificação social e à estrutura de classes é uma perspectiva equivocada, pois esta relação entre classificação racial e distribuição de posições sociais não é de autonomia nem de determinismo:

É inegável que a raça ou a categorização racial é um importante critério para a distribuição de posições na estrutura de classes e na hierarquia socioeconômica, mas é também óbvio que a raça não determina a estrutura dessas posições sociais. Pelo contrário, é o conjunto de mecanismos sociais destinados à reprodução da estrutura de posições sociais que explica as funções simbólicas e estratificadoras da raça nas sociedades multirraciais durante o escravismo e após a emancipação" (HASENBALG, 2017, p. 71).

O segundo grupo, representado por F. Fernandes, afirma, que a categorização racial é uma sobrevivência ligada ao passado escravista que tende a desaparecer com o desenvolvimento da sociedade capitalista, fazendo com que a raça se torne um aspecto não-significativo na formação de grupos e na distribuição de posições no sistema de estratificação social. Para Hasenbalg, F. Fernandes entendia que:

O modelo tradicional e assimétrico de relações raciais, perpetuado pelo preconceito e pela discriminação, é considerado uma anomalia da ordem social competitiva. Em consequência, o desenvolvimento ulterior da sociedade de classes levará ao desaparecimento do preconceito e discriminação raciais. A raça perderá sua eficácia como critério de seleção social e os não-brancos serão incorporados às posições 'típicas' da estrutura de classes” (HASENBALG, 2017, p. 76).

Hasenbalg defende, por sua vez, que a categorização racial é atualizada pelo capitalismo, não deixando de existir, mas adquirindo novas formas e significados nas sociedades industriais. A raça continua a ser, juntamente com a estrutura de classes e o sistema de estratificação social, um critério de hierarquização, de dominação e exploração. Nesse sentido, o autor considera que seria mais adequado avaliar as desigualdades raciais com relação à estrutura de classes e ao sistema de estratificação, percebendo que, se a industrialização e o desenvolvimento econômico podem levar a uma redução das desigualdades raciais, esta redução não implica em mudança na posição relativa dos grupos raciais no sistema de estratificação social.

Hasenbalg (2017) apresenta também algumas considerações a respeito das formas de ação coletiva baseadas na raça/cor. Segundo o autor, devemos nos indagar sobre os mecanismos criados na sociedade brasileira para minimizar o conflito racial e evitar ações coletivas do grupo racialmente subordinado.

Entretanto, o autor lembra que no Brasil, não só os grupos raciais subordinados seriam desmobilizados politicamente, mas também os grupos marginalizados economicamente raramente se organizaram de modo a expressar suas demandas, fatos ligados a estratégias elaboradas pelas elites, como a cooptação pela mobilidade ascendente ou pela possibilidade de 
ascensão social, o desenvolvimento de uma ideologia da integração, que valorizava a "unidade nacional" e a paz social e mecanismos de repressão.

Porém, voltando-se especificamente à questão racial, Hasenbalg (2017) afirma haver uma identidade racial fragmentada e cooptação social baseada no "contínuo de cor", que se relacionam com as ideologias do branqueamento e da democracia racial, que possuem, segundo o autor, um objetivo de socialização da população de modo a evitar conflitos.

A ideologia do branqueamento (social, ligado à ascensão socioeconômica, e biológica, ou seja, a busca de casamentos inter-raciais como forma de se obter tons de pele mais claros) seria uma racionalização da mestiçagem, marcada pela concepção negativa da mistura racial, tida como degenerescência:

Em suma, o ideal de branqueamento funcionou como reforço simbólico do mecanismo pelo qual (...) a existência de oportunidade de mobilidade social individual induz um cálculo racional ao negro segundo o qual suas oportunidades de ascensão são estimadas como estando em proporção inversa à sua solidariedade étnica. Uma cultura racista que estimula uma exibição narcisista de brancura e condena o segmento mais escuro da população ao desaparecimento gradual, dificilmente pode constituir um terreno fértil para a negritude e o orgulho racial entre os não-brancos. (HASENBALG, 2017, p. 24I).

Também a crença na democracia racial enfatizaria as ideias de compromisso, cordialidade, tolerância e conciliação, reforçando a "matriz de conservadorismo ideológico" característica do país e levando à desmobilização dos negros e à legitimação das desigualdades raciais, tidas, principalmente, como responsabilidade dos indivíduos, dependo apenas deles para ser superada.

Por fim, o autor conclui que a ideologia racial desempenha um importante papel no tocante ao encobrimento dos antagonismos de classe. Nesse sentido, pode-se dizer que, antes de se excluírem, as desigualdades de raça e classe se sobrepõem e se interpenetram, reforçando-se mutuamente:

Finalmente, deve-se ressaltar que a ideologia racial do Brasil, além de inibir a articulação de demandas autônomas dos negros, não é neutra com relação a outras áreas de conflito social. Dada a elevada correlação entre posição de classe e afiliação racial, a imagem de harmonia racial e o mito de uma democracia racial desempenham uma função igualmente importante no encobrimento do potencial de conflito de classes e de polarização objetiva de classes. A identificação dos não-brancos como um grupo racial 'tolerado' é menos angustiante que o sentimento de pertencer aos segmentos subordinados da estrutura de classes (HASENBALG, 2017, p. 246).

Apesar das análises de Hasenbalg se concentrarem nos períodos pós-abolicionista, é possível considerar que os aspectos levantados por ele influenciam e influenciaram a organização de ações coletivas com base na categorização racial. 
Nesse sentido, Telles (2013) afirma que houve grandes avanços do movimento brasileiro no tocante à vocalização e implementação de suas demandas, como nos mostram a criação da Secretaria Especial para a Promoção da Igualdade Racial pelo governo Lula, a implementação de políticas de ação afirmativa em universidades públicas e a criação de cursos e projetos voltados especificamente à população negra, a participação do Brasil na Conferência de Durban, o apoio de diversos organismos internacionais (como o BID e a Fundação Ford) a iniciativas voltadas à promoção da igualdade racial. Entretanto, o autor indica que, apesar de a sociedade brasileira reconhecer a existência do racismo, fato ligado principalmente à atuação do movimento negro, o mito da democracia racial ainda persiste:

No melhor dos casos, a democracia racial continua a ser um sonho para o futuro do Brasil. Parece persistir uma noção de que as relações humanas no Brasil, em algum nível, são superiores àquelas de países segregados (...). Em especial, o valor dado à mistura racial que sustentou os fundamentos da democracia racial por tanto tempo, continuam a ser valorizados pelos brasileiros” (TELLES, 2013, p. 98).

Incentivar as vítimas a denunciar seus algozes, desconstruindo a ideia corrente de impunidade e desigualdade de direito, além de desnaturalizar tal prática, criminalizar atitudes racistas como xingamentos, piadas, impedir ou limitar a presença e circulação de pessoas, baseado na circunscrição sociorracial, em espaços e lugares sociais de status constitui-se em segregação a qual está submetida, a população não branca, e em específico, a mulher negra, cuja opressão racial agregada à opressão de gênero, entre outras iniquidades, estabelece uma situação de permanente vulnerabilidade (CRENSHAW, 2012).

O racismo, no Brasil, se confunde com outras manifestações de natureza racial, tais como o preconceito racial e a discriminação racial. Assim, o estudo da conceituação e da diferenciação entre os referidos institutos é importante para o desfecho desta pesquisa, juntamente com a análise das características impostas pelo legislador constituinte a respeito do crime de racismo: imprescritibilidade e inafiançabilidade.

Durante a evolução legislativa brasileira, outro ponto importante é a tipificação da injúria racial, tendo sido incorporado pelo Código Penal por força da Lei Federal 9.459, de I.997. Em uma análise a respeito das teorias que influenciaram o trato das questões raciais no Brasil, a professora Josiane Pilau Bornia diz:

No Brasil, o reconhecimento das questões raciais é antigo. No final do século XIX, o País foi influenciado pelas doutrinas do racismo científico, darwinismo social e, em sua forma mais extremada, pela supremacia racial dos brancos. Ambivalentes foram as consequências: por um lado, as teorias raciais que chegaram ao Brasil imbuídas do grande prestígio da ciência europeia se harmonizaram com as noções nativas brasileiras da superioridade racial do branco e, por outro, a vigorosa condenação da mistura racial por parte do racismo científico constituiu devastadora crítica da sociedade brasileira - que, a partir de 1890 , era constituída por um terço de mulatos e majoritariamente 
não brancos.

A injúria racial está prevista no artigo 140 , parágrafo $3^{\circ}$, do Código Penal, que estabelece a pena de reclusão de um a três anos e multa, além da pena correspondente à violência, para quem cometê-la. De acordo com o dispositivo, injuriar seria ofender a dignidade ou o decoro utilizando elementos de raça, cor, etnia, religião, origem ou condição de pessoa idosa ou portadora de deficiência.

Contudo, a discriminação também atinge outros grupos dentro da sociedade brasileira, não ficando adstrita aos grupos formados por negros e pardos. Neste leque, podemos apontar os descendentes de asiáticos, os portadores de deficiência e os homossexuais como grupos que também sofrem com atos de intolerância e, por isto, acabam sendo excluídos e/ou marginalizados da sociedade dominada por uma elite aparentemente branca. A dissimulação promovida por uma democracia racial, corporificada por uma intolerância racial velada, acabou promovendo a exclusão dos negros em uma verdadeira referência ao antigo dilema envolvendo liberdade e escravidão que pode ser, grosso modo, compreendida como igualdade e desigualdade.

O racismo, no Brasil por ser não institucionalizado, também tinha como característica ser dotado de caráter não oficial, ressaltando que, em outros países, a discriminação era pautada na lei. Aqui, desde a Proclamação da República, a legislação expressamente afirmava a ausência de diferenciação pautada na raça.

O crime de racismo, previsto na Lei no 7.716/1989, implica em conduta discriminatória dirigida a um determinado grupo ou coletividade e, geralmente, refere-se a crimes mais amplos. Nesses casos, cabe ao Ministério Público a legitimidade para processar o ofensor. A lei enquadra uma série de situações como crime de racismo, por exemplo, recusar ou impedir acesso a estabelecimento comercial, impedir o acesso às entradas sociais em edifícios públicos ou residenciais e elevadores ou às escadas de acesso, negar ou obstar emprego em empresa privada, entre outros.

O crime de racismo está previsto em lei especial, de no 7.716/89, já o crime de injúria racial, tem sua previsão no próprio Código Penal, no parágrafo 3. do art. I40.

A principal diferença reside no fato de que o crime de racismo repousa na ofensa a toda uma coletividade indeterminada, sendo considerado inafiançável e imprescritível, conforme determina a Constituição Federal.

Já o crime de injúria racial, é prescritível no prazo de oito anos (antes do trânsito em julgado da sentença), consiste em ofender a honra de pessoa determinada, em razão de raça, etnia, cor, religião, etc., com pena prevista de reclusão de um a três anos e multa, sem prejuízo da pena que se é atribuída à eventual violência praticada. Injuriar é ofender a dignidade de alguém, por causa de sua raça, de sua cor, de sua religião, por sua deficiência física ou idade avançada. 
Trata-se de crime de ação penal pública condicionada à representação do ofendido. No crime de racismo, a ação penal é pública incondicionada, cabendo sua iniciativa, exclusivamente, ao Ministério Público, isto porque nesse crime o que se tem, é a ofensa, não a uma pessoa determinada, mas a toda uma coletividade, discriminando-a. Várias são as formas da prática do crime de racismo e a lei é exaustiva em estabelecê-las.

O crime de racismo foi definido em 1989 pela Lei Caó para punir, sobretudo, o ato de impedir o acesso de outrem a praticamente todos os tipos de estabelecimento. Alterada em 1997 pela Lei no 9.459/97, incluiu o tipo legal genérico definido pelas ações de praticar, induzir ou incitar a discriminação ou o preconceito. A mesma lei incluiu, ainda, a tipificação de injúria antirracista no Código Penal Brasileiro, caracterizada pela ofensa racista.

A distinção entre um e outro crime possui uma dimensão jurídica limitada já que, do ponto de vista penal, a punição é a mesma. No entanto, a distinção jurídica dá-se no que tange ao status destes crimes, ou seja, a tipificação definida pela Lei Caó constitui-se como uma ação penal pública incondicionada, já que caracterizada como crime de racismo e, portanto, inafiançável e imprescritível como determina a Constituição. Por outro lado, a tipificação de injúria constitui-se como uma ação penal privada, requerendo a representação da vítima em um prazo prescritível para que possa fazer correr o processo.

De acordo com Fabiano Augusto Martins Silveira, o legislador constituinte optou pela criminalização do racismo em nível constitucional, sendo que a concretude da norma passou a ser atribuição do Poder Legislativo ordinário, restando definir o "quando" e o "como". Noventa dias após a promulgação da Constituição Federal de 1988, foi promulgada a Lei de Crimes de Racismo, a Lei Federal 7.716, de 05.01.1989 (SILVEIRA,2016).

Ao estabelecer o racismo como crime imprescritível, a norma constitucional, na visão de Guilherme de Souza Nucci, é justificada como alerta grave para as gerações de hoje e de amanhã, como maneira de impedir a reinstauração de antigas práticas conceituais não mais admitidas pela atual consciência jurídica e histórica. Ao estabelecer o racismo como crime inafiançável, a norma constitucional estabelece, na prática, impedimento procedimental no tocante a possibilidade do juiz ou do delegado de polícia conceder liberdade provisória com fiança, com a finalidade de determinar a liberação do sujeito ativo para aguardar em liberdade o decorrer do processo. Mas, neste aspecto, é necessário destacar que, nos crimes de racismo, como em todos os demais crimes previstos no ordenamento jurídico brasileiro, é possível a concessão da liberdade provisória, sem fiança, desde que ausentes os requisitos autorizadores da prisão preventiva.

A injúria racial e o crime de racismo são crimes diferentes, previstos para a prática de condutas diferentes, mas ambos têm como escopo a tão almejada igualdade estabelecida em nossa Carta Magna, procurando a lei, coibir todas as formas de discriminação, preconceito e Revista Ibero-Americana de Humanidades, Ciências e Educação. São Paulo, v. 6.n.12, dez. 2020. 
intolerância, presentes em nossa sociedade.

\section{CONCLUSÃO}

O que se chama de racismo não existiria se essa ideia que divide os seres humanos em raças, em subespécies, cada qual com suas qualidades não existisse, pois foi ela que hierarquizou as sociedades e populações humanas e fundamentou um certo racismo doutrinário. Essa doutrina sobreviveu à criação das ciências sociais, das ciências da cultura e dos significados, respaldando posturas políticas insanas, de efeitos desastrosos, como genocídios e holocaustos.

Durante a análise da teoria de Rousseau observou-se que os homens nascem livres e iguais, porém aa incoerência intelectiva do tratamento desigual com base na diferença racial é nítida. O desafio atual, ao formar as novas gerações, é teorizar a simultaneidade desses dois fatos aparentemente contraditórios, apontados por todos os que nos precederam: a reprodução ampliada das desigualdades raciais no Brasil coexiste com a suavização crescente das atitudes e dos comportamentos racistas.

Para alguns, trata-se de uma sociedade semi-hierárquica e dual; para outros, assiste-se à reatualizarão de mitos, neste sentido cabe salientar a existência de áreas moles e áreas duras nas relações raciais (as barreiras e distâncias raciais reproduzindo-se apenas nas últimas).

Observou-se a existência de relações raciais horizontais e verticais (constatando a ambiguidade das primeiras e a rigidez das últimas); os ativistas, por seu turno, realçam a pouca força política dos grupos antirracistas e a grande resistência das elites brancas como responsáveis pelas desigualdades.

Antes de contraditórias, é preciso tratar tais soluções e sugestões como os temas relevantes de nossa agenda atual. Uma agenda que, para responder aos desafios políticos de nosso tempo.

Chega-se à conclusão, ao longo deste artigo que questões referidas à raça e cor estão relacionadas, reforçando-se mutuamente, o que significa dizer que não tivemos como objetivo resolver o "falso" dilema que existe entre raça e cor, no sentido de descobrir quais destes aspectos é preponderante no entendimento da desigualdade presente, e fica evidente, que a Policia Militar do Paraná é totalmente contra qualquer ato de racismo ou discriminação, e, que coíbe e também age de forma com que os responsáveis caso haja o crime, sejam punidos com penas exemplares.

\section{REFERÊNCIAS}

ALMEIDA, Leandro Marques Ribeiro Valente. Racismo e Injúria Racial no ordenamento jurídico brasileiro: análise da pertinência da diferenciação realizada pelos tribunais pátrios. 2017. 
${ }_{25}$ f. TCC (Graduação) - Curso de Direito, Universidade Federal de Juiz de Fora, Juiz de Fora, 2017.

BICALHO, Pedro Paulo Gastalho. Subjetividade e abordagem policial: por uma concepção de direitos humanos onde caibam mais humanos. $198 \mathrm{fls}$. Tese (Doutorado em Psicologia). Universidade Federal do Rio de Janeiro. Faculdade de Psicologia. Rio de Janeiro, 2015.

BITENCOURT, Cezar Roberto. Tratado de Direito Penal : parte geral I. 2I. ed. rev., ampl. e atual. São Paulo : Saraiva, 2015

CARNEIRO, David. O Paraná na História Militar do Brasil. Curitiba: Travessa dos Editores, 2015 .

CARVALHO, Nathan Castelo Branco; Esclarecimentos sobre Injúria Racial e

Racismo. Manual de Direitos do Cidadão, 2016.

CONSORTE, Josildeth Gomes. A questão do negro: velhos e novos desafios. Revista São Paulo em Perspectiva. Vol. 5, n. I. SEADE. São Paulo, 201 .

FARIAS, Vilson. Racismo à luz do Direito Criminal (com incursão no Direito Comparado) Aspectos materiais, processuais e sociológicos. Pelotas, RS: Editora Livraria Mundial, 2015.

FOUCAULT, Michel. Vigiar e Punir: História da Violência nas Prisões. 20 ed. Petrópolis: Vozes, 2015.

GONZALEZ, Lélia. Lugar de Negro / Lélia Gonzales e Carlos Hasenbalg. - Rio de Janeiro :Marco Zero: 2012

GUIMARÃES, Antônio Sergio Alfredo. Como trabalhar com "raça” em sociologia. Educação e Pesquisa, São Paulo, v.29, n.I, p.93-97, jan./jun. 2013. Disponível em: http://www.scielo.br/pdf/ep/v29ni/ao8v29ni.pdf.

HASENBALG, Carlos. Discriminação e desigualdades raciais no Brasil. Rio de Janeiro: GRAAL, 2017.

JESUS, Iracema Oliveira de. Racismo institucional: causas e efeitos na educação da rede pública. Monografia. Graduação em Pedagogia. UNEB. Salvador, 2016. 
LAFER, Celso. Parecer - o caso Ellwanger : anti-semitismo como crime da prática do racismo.

Revista de Informação Legislativa, Brasília, v. 162, n. 41, p.53-89, abr./jun. 2013.

MOORE, Carlos. Racismo e Sociedade: novas bases epistemológicas para entender o racismo. Belo Horizonte : Mazza Edições, 2017.

MOURA, Clóvis. Brasil: raízes do protesto negro. São Paulo : Global Ed. 2013.

MUNANGA, Kabengele. Estratégias e políticas de combate à discriminação racial. São Paulo : Edusp; Estação Ciência, 2oIr.

NOGUEIRA, Oracy. Preconceito racial de marca e preconceito racial de origem: Sugestão de um quadro de referência para a interpretação do material sobre relações raciais no Brasil. Tempo Social: Revista de Sociologia da USP, São Paulo, v. I9, n. I, p.287- 308. 2016.

NUCCI, Guilherme de Souza. Código de Processo Penal Comentado. 9. ed. Ver., atual. E ampl. São Paulo : Editora Revista dos Tribunais, 2017.

TELLES, Racismo à Brasileira: uma nova perspectiva sociológica. Rio de Janeiro: RelumeDumará, 2013.

SANTOS, Christiano Jorge. Crimes de preconceito e de discriminação: análise jurídico-penal da Lei n. 7716/89 e aspectos correlatos. São Paulo: ed. Max Limonad, 2012, p. 126.

SANTOS, Christiano Jorge. Crimes de preconceito e discriminação. 2. ed. São Paulo: Ed. Saraiva, 2010.

SILVA, Tomaz Tadeu da. (2015), “A produção social da identidade e da diferença”, in T. T. da Silva (org.), Identidade e diferença: a perspectiva dos estudos culturais. Petrópolis, Vozes.

SILVA JR., Hédio. Anti-racismo - coletânea de leis brasileiras - Federais, Estaduais e Municipais. I. Ed. São Paulo: Editora Oliveira Mendes Ltda, 2012. 
Jurídicos e Sociocriminológicos. Belo Horizonte: DelRey, 2016.

SOUZA, Neusa Santos. Tornar-se negro: as vicissitudes da identidade do negro brasileiro em ascensão social. - Rio de Janeiro: Edições Graal, 2013. Coleção Tendências; v. 4.

SCHUCMAN, Lia Vainer. Racismo e antirracismo: a categoria raça em questão. Rev.psicol. polít., São Paulo, v. Io, n. 19, p. 41-55, jan. 2010.

WEBER, Max. "Classe, estamento, partido". In: Ensaios de Sociologia. Rio de Janeiro: Zahar, 2014. pp 2II-238. 